\title{
The MIIND framework: combining population density methods, neural simulations and Wilson-Cowan dynamics into large-scale heterogeneous neural models of cognition
}

\author{
Marc de Kamps*1 and Frank van der Velde ${ }^{2}$
}

\author{
Address: ${ }^{1}$ School of Computing, University of Leeds, Leeds, LS2 9JT, UK and ${ }^{2}$ Cognitive Psychology, Leiden University, Leiden, $2333 \mathrm{AK}$, the \\ Netherlands \\ Email: Marc de Kamps* - dekamps@comp.leeds.ac.uk \\ * Corresponding author
}

from Eighteenth Annual Computational Neuroscience Meeting: CNS*2009

Berlin, Germany. 18-23 July 2009

Published: 13 July 2009

BMC Neuroscience 2009, I0(Suppl I):P276 doi:I0.1186/I47I-2202-10-SI-P276

This abstract is available from: http://www.biomedcentral.com//47I-2202/I0/SI/P276

(C) 2009 de Kamps and Velde; licensee BioMed Central Ltd.

\begin{abstract}
Introduction
Considerable effort is spent on large-scale neural models of brain behavior. These models are often very different and may simulate phenomena as varied as vision attention, working memory, etc. From a mathematical point of view they are usually very similar: mostly they are systems of coupled Wilson-Cowan equations, or Fokker-Plancklike equations when population density techniques (PDTs) are considered. The MIIND framework [1] allows the simulation of network processes in terms of Algorithms. The task of setting up the simulation of a largescale network becomes trivial: one only has to specify the nodes in the network and their connections and to endow the nodes with the appropriate Algorithm. Since WilsonCowan algorithms and PDTs are provided with MIIND, a large number of models described in the literature can be easily replicated. Novel simulations can be configured very quickly because of MIIND's Python interface. A novel simulation of neural dynamics (e.g. a new simulator) only needs to be defined at the node level: as soon as it is provided with an Algorithm interface, large networks can be created on the fly.
\end{abstract}

\section{Background}

MIIND provides algorithms to simulate Wilson-Cowan dynamics, PDTs as described by Knight [2] and coworkers and by many others. In particular the algorithms provided for leaky-integrate-and-fire (LIF) neurons (which are closely related to Fokker-Planck equations describing the Ornstein-Uhlenbeck process) are probably the most efficient that are currently around $[3,4]$ and one of the few which are available as Open Source code. Also some neuronal gain functions are available, which together with Wilson-Cowan dynamics can replicate neural population behaviour in considerable detail [5]. MIIND is implemented as a $\mathrm{C}++$ framework with a SWIG-generated Python interface, which keeps the computationally most demanding algorithms efficient. It relies on the ROOT [6] for data storage and visualization.

\section{Discussion}

We will present several examples of novel cognitive models [7] and replications of published models (e.g. [8]). Most important issues in the current development of MIIND are the parallelization of the central simulation loop and the further development and implementation PDTs that go beyond LIF neurons and are able to deal with synaptic kinetics and spike-rate adaptation. MIIND now provides an interface to NEST [9], so that large-scale network models can be created which include Monte Carlo simulations. Algorithms can be exchanged in run time so that different simulations of neuronal dynamics can be directly compared within the same network model. It is also possible to create heterogeneous networks having different parts of the network are simulated by different simulators. 


\section{References}

I. de Kamps M, Baier V, Drever J, Dietz M, Mösenlechner L, Velde F van der: The state of MIIND. Neur Netw 2008, 2 I: I 164-I I8I.

2. Omurtag A, Knight BW, Sirovich L: On the simulation of large populations of neurons. Jour Comp Neurosc 200I, 8:5I-63.

3. de Kamps M: An analytic solution of the reentrant Poisson master equation and its application in the simulation of large groups of spiking neurons. Proc IJCNN 2006:102-109.

4. de Kamps M: A simple and stable solution for the population density equation. Neur Comp 2003, 15:2129-2146.

5. La Camera G, Rauch A, Lüscher H-R, Senn W, Fusi S: Minimal models of adapted neuronal response to in vivo-like input currents. Neur Comput 2004, 16:2101-2124.

6. ROOT, An object-oriented data analysis framework [http:// root.cern.ch]

7. de Kamps M, Velde F van der, Harrison D: A neuro-dynamical model for global saliency. . In preparation

8. Brunel N: Persistent activity and the single-cell frequency-current curve in a cortical network model. Network 2000, I I:26I-280.

9. Gewaltig M-O, Diesmann M: NEST (Neural Simulation Tool). Scholarpedia 2007, 2: I430-I434.

Publish with Biomed Central and every scientist can read your work free of charge

"BioMed Central will be the most significant development for disseminating the results of biomedical research in our lifetime. "

Sir Paul Nurse, Cancer Research UK

Your research papers will be:

- available free of charge to the entire biomedical community

- peer reviewed and published immediately upon acceptance

- cited in PubMed and archived on PubMed Central

- yours - you keep the copyright 